\title{
Clear cell adenocarcinoma of vagina associated with uterine prolapse: A rare entity
}

\author{
Rekha Sachan, Pooja Gupta, Patel ML
}

\begin{abstract}
Introduction: Clear cell adenocarcinoma usually affects the cells of the female genital tract. In this cancer, cells become vacuolated and filled with glycogen hence it is called clear cell. This cancer is insidious and slow growing. Here we report a case of uterine prolapse with polypoidal growth in the vagina which on histopathological examination was diagnosed as a case of clear cell adenocarcinoma of the vagina. Case Report: A 27-year-old women with three previous vaginal deliveries presented with complaint of something coming out pervaginum, associated with bleeding and discharge pervaginum for the last one year. She was diagnosed as a case of uterine prolapse with vaginal clear cell adenocarcinoma. Conclusion: Based on the cases mentioned previously and one reported here vaginal clear cell adenocarcinoma is a rare entity and can also exist even without diethylstilbestrol (DES) exposure in utero.
\end{abstract}

Keywords: Clear cell adenocarcinoma, Vagina, Uterine prolapsed, Excisional biopsy, Radical hysterectomy

$* * * * * * * * *$

Sachan R, Gupta P, Patel ML. Clear cell adenocarcinoma of vagina associated with uterine prolapse: A rare entity.

Rekha Sachan ${ }^{1}$, Pooja Gupta ${ }^{1}$, Patel $\mathrm{ML}^{2}$

Affiliations: ${ }^{1}$ Department of Obstetrics and Gynecology, CSM

Medical University, Lucknow, ${ }^{2}$ Department of Medicine, CSM

Medical University, Lucknow

Corresponding Author: Rekha Sachan, Department of Obstetrics and Gynecology, CSM Medical University, Lucknow; Email: drrekhasachan@gmail.com

Received: 15 May 2012

Accepted: 11 July 2012

Published: 01 March 2013
International Journal of Case Reports and Images 2013;4(3):154-157.

$* * * * * * * * *$

doi:10.5348/ijcri-2013-03-283-CR-4

\section{INTRODUCTION}

Clear cell adenocarcinoma is a rare type of adenocarcinoma. It usually affects the female genital tract. Most commonly it affects the ovary, cervix, and urinary tract including the kidneys [1]. It has been strongly linked to in utero exposure of the female fetus to diethylstilbestrol (DES) [1, 2]. Primary vaginal adenocarcinoma unrelated to DES exposure is very rare [3]. It usually involves anterior or lateral wall of upper vagina or cervix of young females usually in their late teens or early twenties. We hereby report a case of 27year-old female who presented with clinical features suggestive of uterine prolapse with a polypoidal growth which on histopathology was diagnosed as a case of vaginal adenocarcinoma (clear cell variety).

\section{CASE REPORT}

A 27-year-old female patient presented with complaints of something coming out of vaginam for the past one year. It was associated with bleeding and discharges per vaginum for the past one year. She had three previous vaginal deliveries, without any history of abortion. Last delivery was one and half years back. There was no family history suggestive of DES or any toxins exposure. Pallor was present on general examination and all other systems were within normal limits. Inspection of the perineum revealed a polypoidal growth of about $4 \times 4 \mathrm{~cm}$ size coming out of the introitus, originating from the anterior vaginal wall (Figure 1). It was firm to soft in consistency and blead on touch. On per-speculum examination second degree cervical 
descent was present. Growth seemed to arise from the upper one third of anterior vaginal wall in proximity to urethral opening. Cervical lips were free form growth (Figure 2). Vaginal examination revealed a normal sized uterus with no palpable adnexal pathology. On per rectal examination rectal mucosa was free and no parametrial thickening was present. Certain routine and specific investigations were conducted to determine the origin of the growth. Cystoscopic findings were within normal limits. Color Doppler sonography of abdomen did not reveal any evidence of metastasis. Chest X-ray, upper GI endoscopy and colonoscopy were within normal limits. On ultrasonography, excretory system (kidney, urinary bladder and urethra) was normal. On the basis of history and examination the following differential diagnosis were kept in mind: prolapse of uterus with vaginal growth, inversion of uterus, infected cervical polyps, leiomyosarcoma of cervix and vagina. Patient was planned for exicisional biopsy of the growth under anaesthesia. Histopathologic examination of the vaginal growth showed stratified squamous epithelium with subepithelial zone showing malignant epithelial tumor composed of papillae and acini disposed in tubulocystic pattern. The cells were round to oval, with high nucleocytoplasmic ratio and vesicular chromatin, prominent nucleoli, hobnailing and areas of cytoplasmic clearing suggestive of clear cell adenocarcinoma of vagina, without surrounding vaginal adenosis (Figures 3 , and 4). Based on the above findings staging of this case was T1NoMo (Stage I). A radical hysterectomy with vaginectomy with lymph node dissection was done, as patient was willing for removal of the uterus. Histopathology of the specimen showed normal uterine histology. Surrounding vaginal tissue histology showed stratified squamous epithelium with underlying stroma showing fibrocollagenous tissue, blood vessels, smooth muscle bundles and interspersed nerve bundles without any malignant cells. Sections from the cervix showed normal histology and lymph nodes were negative for the malignancy. Patient was followed up at three monthly intervals up to nine months. Clinical examination, pap smear and ultrasonography were unremarkable on follow-up.

\section{DISCUSSION}

Vaginal clear cell adenocarcinoma is common in late teens and early second decade in females whose

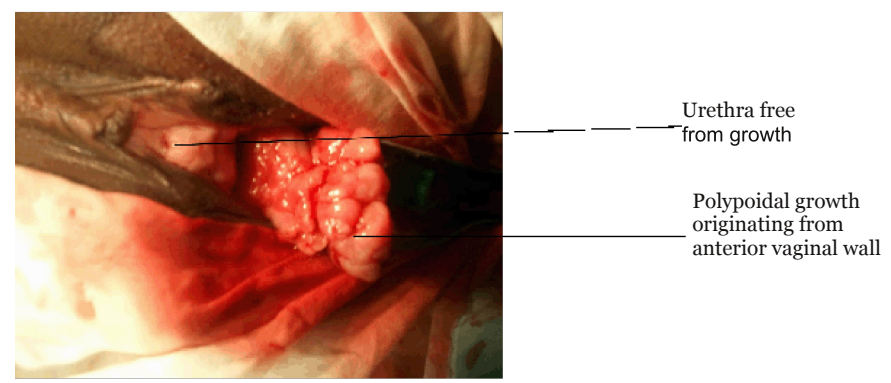

Figure 1: Growth not involving urethra and clitoris. mothers took diethylstilbestrol (DES) during pregnancy [4]. Clear cell adenocarcinoma of vagina account for about $5-10 \%$ of all vaginal cancers [3]. The absolute risk

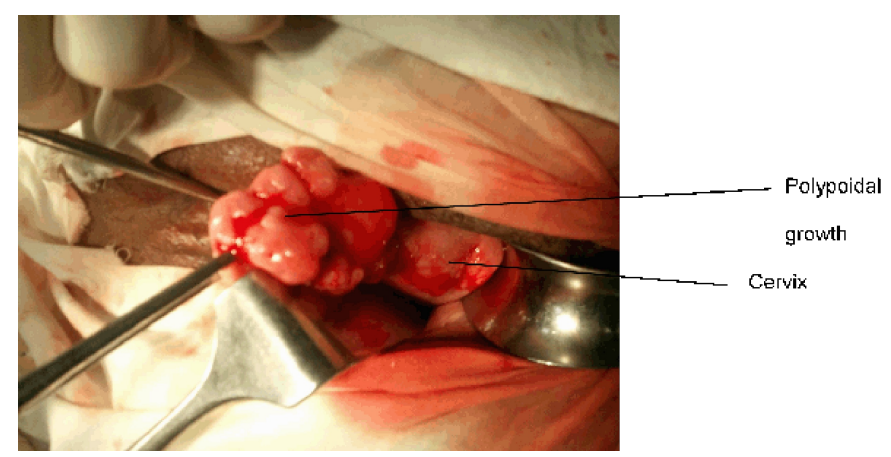

Figure 2: Growth not originating from the cervix.

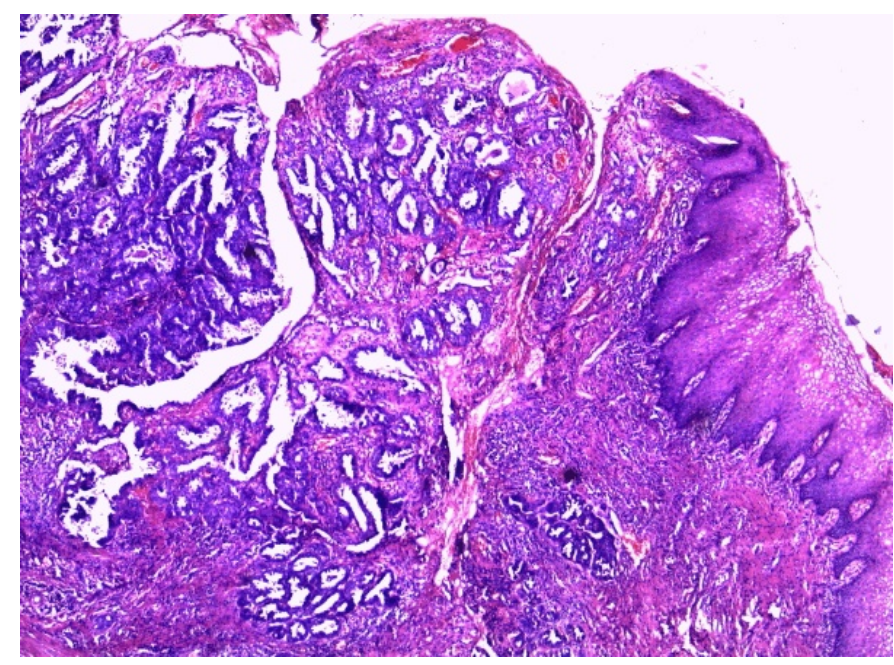

Figure 3: Histopathology of clear cell adenocarcinoma and normal vaginal epithelium without adenosis (H\&E stain, 100x).

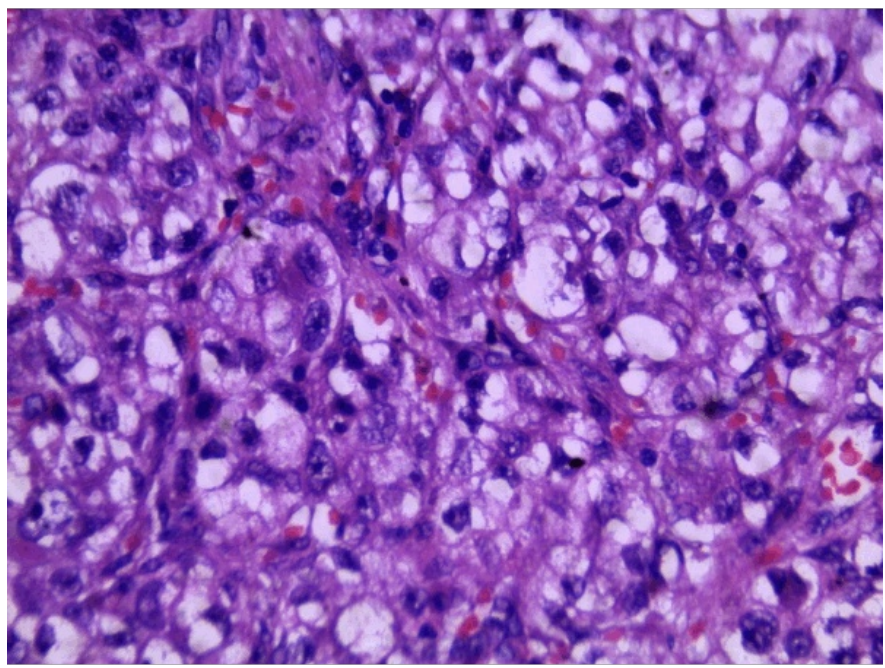

Figure 4: Papillae and acini disposed in tubulocystic pattern, with round to oval cells, with high nucleocytoplasmic ratio, prominent nucleoli, hobnailing and areas of cytoplasmic clearing (H\&E stain, 400x). 
of clear cell adenocarcinoma of vagina in the daughters of DES exposed mothers is 1 in 1000 [5]. In our patient's mother there was no past history of in utero exposure to DES. Clear cell adenocarcinoma of the vagina most frequently arises from vaginal mucosa but may arises from the cervix. It may possibly be derived from vaginal adenosis, but in our case no vaginal adenosis was seen. The tumor size is variable ranging from microscopic to large size. Most of the larger tumors are polypoidal or nodular in appearance and are mostly superficially invasive. Our case is rare because the patient developed primary vaginal clear cell adenocarcinoma, which was not associated with DES exposure in the mother. Furthermore it is the rare reported case in Indian scenario. The diagnosis was made based on the excisional biopsy of vaginal growth which on histopathological examination showed characteristic rounded cells with clear appearance of cytoplasm, high nucleocytoplasmic ratio with hobnailing and normal histpathologic examination of cervix, uterus and ovaries after radical hysterectomy with vaginectomy. In this cancare, the cells become vacuolated and filled with glycogen, hence the term 'clear cell' is given to this cancer. There are a few reported cases of vaginal clear cell adenocarcinoma in which there was no in utero exposure to diethylstilbestrol. Wantanabe et al. also reported a case of advanced primary vaginal clear cell adenocarcinoma not associated with DES exposure in a postmenopausal woman [2]. Nordiqvist et al. reviewed twenty one cases of vaginal and cervical clear cell adenocarcinomas, out of which thirteen had no prior exposure to DES [6]. Zeshan-ud-din et al. reported a case of vaginal clear cell adenocarcinoma with associated mullerian duct anomalies, renal agenesis and situs inversus, with no known in-utero exposure with diethylstilboestrol [7], but in our case no mullerian and renal anomalies were found.

\section{CONCLUSION}

Vaginal clear cell adenocarcinoma is a rare entity and can also exist even without diethylstilbestrol exposure in utero.

$$
* * * * * * * * *
$$

\section{Author Contributions}

Rekha Sachan - Substantial contributions to conception and design, acquisition of data, Drafting the article, revising it critically for important intellectual content, Final approval of the version to be published Pooja Gupta - Substantial contributions to conception and design, acquisition of data, revising it critically for important intellectual content, Final approval of the version to be published

Patel ML - Substantial contributions to Drafting the article

\section{Guarantor}

The corresponding author is the guarantor of submission.

\section{Conflict of Interest}

Authors declare no conflict of interest.

\section{Copyright}

(C) Rekha Sachan et al. 2013; This article is distributed under the terms of Creative Commons attribution 3.0 License which permits unrestricted use, distribution and reproduction in any means provided the original authors and original publisher are properly credited. (Please see www.ijcasereportsandimages.com /copyright-policy.php for more information.)

\section{REFERENCES}

1. Guzin K, Eser SK, Yigit A, Zemheri E. Primary clear cell carcinoma of the vagina that is not related to in utero diethylstilbestrol use. Gynecol Surg 2006;3:281-4.

2. Watanabe $\mathrm{Y}$, Ueda $\mathrm{H}$, Nozaki K, et al. Advanced primary clear cell carcinoma of the vagina not associated with diethylstilbestrol. Acta Cytol 2002 May-Jun;46(3):577-81.

3. Tanaka H, Tabata $\mathrm{T}$, Yanase $\mathrm{H}$, et al. Clear cell adenocarcinoma of the vagina in a young female, treated by combination chemotherapy (local and systemic chemotherapy), complicated with chromosomal abnormality. Gynecol Oncol 1994;55:259-64.

4. Hatch EE, Palmer JR, Titus-Ernstoof L, et al. Cancer risk in women exposed to diethylstilbestrol in utero. JAMA 1998;280(7):630-4.

5. Herbst AL, Andersond D. Clear cell adenocarcinoma of the vagina and cervix secondary to intrauterine exposure to diethylstilbestrol. Semin Surg Oncol 1990;6:343-6.

6. Nordqvist SR, Fidler WJ Jr, Woodruff JM, Lewis JL Jr. Clear cell adenocarcinoma of the cervix and vagina. A clinicopathologic study of 21 cases with and without a history of maternal ingestion of estrogens. Cancer 1976;37:858-71.

7. Zeeshan-ud-din, Aamir Ahsan. Vaginal clear cell adenocarcinoma with associated mullerian duct anomalies and situs inversus: Report of a case with no known in-utero exposure with Diethyl stilbesterol. J Pak Med Assoc 2009 Aug;59(8):568-70. 
Access full text article on other devices

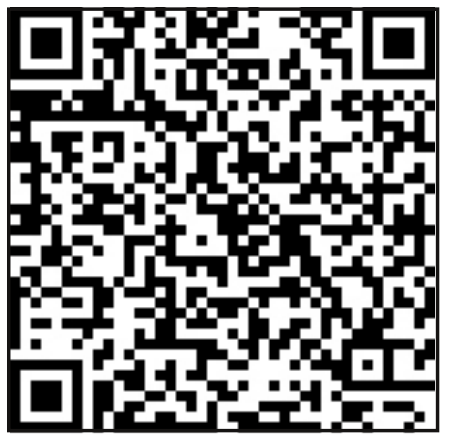

Access PDF of article on other devices

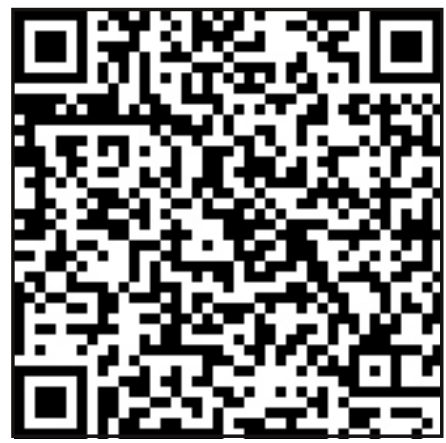

